\title{
Acústica e música: uma abordagem metodológica para explorar sons emitidos por tubos sonoros ${ }^{+*}$
}

Suzana Maria Coelho ${ }^{1}$

Faculdade de Física - PUC

Gisele Ramires Machado ${ }^{2}$

Licencianda da Faculdade de Física - PUC

Porto Alegre - RS

\section{Resumo}

Este artigo relata uma oficina realizada com alunos do Curso de Física na qual se propôs a montagem de um móbile com tubos sonoros na busca da caracterização de sons e abordagem dos princípios físicos envolvidos nos fenômenos acústicos. Partindo do exercício da percepção auditiva, possibilitou-se uma comparação entre os sons emitidos pelo móbile e os de instrumentos musicais. Além disso, realizaram-se medições com afinadores digitais e virtuais, esses resultados tendo sido confrontados aos provenientes da modelização matemática. A metodologia utilizada sugere várias óticas para o ensino de um mesmo fenômeno, cujo caráter interdisciplinar permite relacionar diferentes saberes e suas aplicações.

Palavras-chave: Acústica; Música; Metodologia do Ensino de Física.

\begin{abstract}
The present article describes a workshop with Physics students, in which the assembly of a mobile was proposed, by using sound pipes to pursue sound characterization and an approach to the Physic s principles involved in acoustic phenomena. The comparison between the sounds emitted by the mobile and musical instruments was possible through

\footnotetext{
Accustics and music: a methodological approach to explore sounds emitted by sound pipes

* Recebido: outubro de 2014.

Aceito: dezembro de 2014.

1 E-mail: suzanacoelho@terra.com.br

2 E-mail: gicaramires@gmail.com
} 
aural perception exercises. Besides, measurements were carried out using virtual and digital tuners; such results have been compared with the results from Mathematical Modelling. The methodology used suggests several ways to teach the same phenomenon, whose interdisciplinary characteristic allows one to relate different kinds of knowledge and their application.

Keywords: Acoustics; Music; Physics Teaching Methodology.

\section{Introdução}

O artigo considera uma abordagem relacional (LENOIR, 2012) da função da interdisciplinaridade, no sentido de estabelecer elos, construir pontes, buscando na proposta didática apresentada articular conhecimentos de física e música, integrando os saberes disciplinares no ensino de física.

De um ponto de vista epistemológico, é possível perceber como esses elos estão presentes no processo de construção do conhecimento científico, ou seja, o caráter interdisciplinar do conhecimento específico. A interdisciplinaridade não se opõe à disciplinaridade, ao contrário:

\footnotetext{
[...] o conceito de interdisciplinaridade tem seu sentido em um contexto disciplinar: a interdisciplinaridade pressupõe a existência de ao menos duas disciplinas como referência e a presença de uma ação recíproca (GERMAIN, 1991 apud LENOIR, 2012, p. 46).
}

As contribuições de Helmholtz no campo da acústica constituem um belo exemplo da necessidade dessa visão interdisciplinar. Hermann Ludwig Ferdinand von Helmholtz (1821-1894), fisiologista, físico, médico alemão e professor na Universidade de Berlim, realizou importantes descobertas a respeito do timbre e do papel dos harmônicos na música. Seus trabalhos relativos às sensações auditivas e à teoria fisiológica da música, como On the sensations of tone as a physiological basis for the theory of music, reúnem conhecimentos nas interfaces da fisiologia, da física e da música.

Resta-nos pensar se não deveríamos no ensino de física preservar essa característica interdisciplinar evidenciada na pesquisa científica. Admitindo esse ponto de vista, como desenvolvê-la na formação de professores dentro da universidade? Como o professor poderá trabalhar de forma interdisciplinar sem ter vivenciado experiências didáticas que contemplem a prática da interdisciplinaridade durante sua formação docente?

Segundo Piaget (1974, p. 23), “A primeira das lições a extrair das tendências interdisciplinares atuais é a necessidade de uma atenta revisão no tocante às relações futuras entre as ciências chamadas humanas e as ciências chamadas naturais". 
Sob essa perspectiva, o conhecimento seria concebido não como algo que está separado do homem, mas como dependente e influenciado por fatores de natureza humana.

O desdobramento do conhecimento em disciplinas estanques teve seu início mediante uma objetivação da coisa conhecida, de maneira que o sujeito cognoscente pretendeu ver a realidade dissociada de si próprio e até mesmo de seu modo de vê-la. Dessa forma, promoveu-se não apenas a disjunção entre diferentes dimensões e aspectos de um mesmo fenômeno, como também do homem em relação a eles (LÜCK, 2001, p. 30).

Essa dissociação do homem e de sua sensibilidade no processo de apropriação do conhecimento acerca dos fenômenos naturais precisa ser revisada quando se pretende ensinar ciências numa abordagem interdisciplinar.

Segundo Piaget (1974, p. 22), no que se refere à interdisciplinaridade no ensino de ciências, os mestres deveriam estar imbuídos de "um espírito epistemológico bastante amplo a fim de que, sem para tanto negligenciarem o campo da sua especialidade, possa o estudante perceber, de forma continuada, as conexões com o conjunto do sistema das ciências".

Para Pombo (2004), atitudes como curiosidade, vontade de saber, gosto pela colaboração, pelo trabalho em comum e disponibilidade para abandonar o conforto de seu campo de saber disciplinar e se aventurar em outras áreas de conhecimento são necessárias a um professor que se propõe a desenvolver propostas interdisciplinares na prática docente.

Lück (2001, p. 88) reforça esse ponto de vista, quando afirma: “A orientação pelo enfoque interdisciplinar para orientar a prática pedagógica implica em romper hábitos e acomodações, implica em buscar algo novo e desconhecido. É, certamente, um grande desafio".

A aventura na exploração de searas alheias, como a música para o físico, exige obrigatoriamente do professor rompimento com os programas estabelecidos e espírito aberto para aprender novos conceitos na interface entre a sua área de saber e a de outras disciplinas.

A prática interdisciplinar é capaz de desfragmentar a realidade, tanto no plano da pesquisa como no do ensino, como se evidencia na análise epistemológica de trabalhos científicos (HELMHOLTZ, 1954) e como sugere Lück (2001):

A superação da fragmentação, linearidade e artificialização, tanto do processo de produção do conhecimento, como do ensino, bem como o distanciamento de ambos em relação à realidade, é vista como sendo possível, a partir de uma prática interdisciplinar (p. 54).

Uma visão mais abrangente e mais próxima da realidade torna-se possível quando a abordagem dos fenômenos naturais é feita sob um enfoque interdisciplinar: "O enfoque interdisciplinar consiste num esforço de busca da visão global da realidade, como superação das impressões estáticas, e do hábito de pensar fragmentador e simplificador da realidade" (LÜCK, 2001, p. 72). 
Além disso, a complexidade do real vem à tona, pelos diferentes olhares e métodos para perscrutar um fenômeno físico, assim como pelos diferentes modelos matemáticos capazes de representá-lo e descrevê-lo: "O desenvolvimento da ótica interdisciplinar se assenta sobre o entendimento da pluridimensionalidade e complexidade da realidade que, aliás, dá origem às múltiplas representações em áreas e teorias diferentes" (LÜCK, 2001, p. 73).

Segundo Halbwachs (1975), um modelo nunca pode ser considerado como uma situação exata e completa da situação, a procura do verdadeiro modelo sendo contrária ao próprio espírito da ciência experimental.

A abordagem interdisciplinar apresentada neste trabalho contempla de forma implícita questões filosóficas desta natureza, ao mostrar as limitações de um modelo matemático e a impossibilidade de um conhecimento imediato do mundo real. O homem cria um sistema de noções e proposições construindo uma imagem representativa física do universo, a verdade sendo, portanto, relativa, um modelo sendo válido dentro de um campo de aplicação, sistema sempre aberto às possibilidades de ser englobado por modelos mais amplos.

Outro aspecto a relevar na prática interdisciplinar seria o da utilidade do conhecimento e da importância da interligação entre aspectos teóricos e práticos: "Emerge, nesse processo, o desenvolvimento de atitude e consciência de que trabalhando dentro de um sistema de interdisciplinaridade o professor produz conhecimento útil, portanto, interligando teoria e prática [...]" (LÜCK, 2001, p. 34).

Ao relacionar teoria e prática no ensino de física, mostrando a necessidade de existência de uma correspondência entre as previsões do modelo teórico e os resultados experimentais, para a validação do modelo na situação física real, o professor está permitindo ao aluno construir uma concepção epistemológica do funcionamento da ciência.

Segundo Halbwachs (1975):

Um modelo teórico é construído de forma a poder ser colocado em correspondência com uma "situação" física real, isto é, uma série de objetos fisicamente manipuláveis e sobre os quais podemos operar determinadas transformações que constituem uma prática experimental. Na medida em que há um paralelismo (morfismo) entre o sistema das transformações teóricas do modelo e o sistema das transformações experimentais da situação pode se dizer que o modelo representa a situação (1975, p. 20).

É a comparação dos valores calculados na teoria e dos valores medidos na experiência que fornece o teste essencial da validade da teoria, isto é, da exatidão do isomorfismo entre estrutura teórica e estrutura praxeológica (HALBWACHS, 1974, p. 99).

Nos livros-texto, normalmente a acústica é apresentada de forma simplificada e descontextualizada de suas importantes implicações no campo musical (acústica musical).

A proposta apresentada neste artigo contrapõe-se ao ensino tradicional da acústica, no sentido de fugir ao padrão do ensino de ondas em cordas e tubos sonoros abertos e fecha- 
dos. Utiliza a contextualização com fenômenos musicais reais por meio da experimentação, na qual o aluno tem contato sensível com o fenômeno e percebe sua complexidade na abordagem matemática por meio de modelos. Confronta resultados teóricos e experimentais, sendo o modelo matemático que se adequa para descrever o funcionamento de um móbile com tubos sonoros (carrilhão) diferente dos apresentados nos livros para descrever o funcionamento dos tubos abertos e fechados.

A escolha do móbile justifica-se por sua similaridade ao carrilhão, instrumento musical utilizado nas orquestras sinfônicas e que, portanto, tem uma aplicação no universo artístico-cultural e não se restringe ao plano especificamente científico. É um dispositivo de fácil acesso, construído com material de baixo custo, presente no quotidiano, e cujo funcionamento se relaciona a uma aplicação tecnológica no campo da música, o carrilhão.

\section{Oficina}

\section{II.1 Contexto}

A oficina Ciência e Música: explorando sons e aguçando a percepção musical, oferecida como atividade da Semana Acadêmica na Faculdade de Física da Pontifícia Universidade Católica do Rio Grande do Sul, teve como público alvo alunos do Curso de Física visando a uma formação docente complementar. Foram realizados dois encontros de aproximadamente duas horas para dois grupos distintos de oito alunos, ministrados por um professor e um bolsista de iniciação científica.

\section{II.2 Abordagem metodológica}

A metodologia utilizada contemplou diferentes visões de um mesmo fenômeno, baseadas na percepção, na medição e na modelização matemática (visão multipolar).

A proposta foi apresentada aos participantes (com o auxílio do programa Microsoft PowerPoint( $\left.{ }^{\circledR}\right)$, focando inicialmente aspectos históricos referentes ao carrilhão - originário do sudeste asiático e construído com bambus. Salientou-se a aplicação tecnológica dos tubos sonoros - hoje de aço ou latão, abertos em ambos os lados - tocados por meio de percussão dentro da orquestra sinfônica. Justificou-se também a escolha do móbile para estudar os princípios de funcionamento do carrilhão por sua similaridade ao mesmo, pela facilidade de construção com materiais de baixo custo e por estar presente no cotidiano. Após essa contextualização, apresentou-se o plano da oficina como segue:

- montagem de um móbile com tubos sonoros;

- caracterização de sons, por meio da percepção auditiva pela comparação entre sons emitidos pelos tubos sonoros e por instrumentos musicais e também por medição com afinadores;

- modelização dos fenômenos físicos;

- o carrilhão na orquestra e 
- exploração didática para possível aplicação no ensino de física.

No corpo deste artigo são enfocados aspectos descritivos referentes a essas etapas, bem como reflexões considerando o caráter interdisciplinar da abordagem didática, as possibilidades da proposta e as reações dos participantes.

As atividades foram desenvolvidas em grupos formados a partir de um questionamento prévio acerca do conhecimento de música dos participantes. Com base nessa informação, foram organizados dois grupos com quatro alunos, cada grupo com pelo menos um aluno iniciado em algum conhecimento musical. Esse procedimento visou facilitar o estabelecimento de elos entre a ciência e a música e a aquisição de conceitos nessa fronteira.

\section{II.2.1 Montagem do móbile}

Foram utilizados os seguintes materiais na construção do móbile:

1. tubos de alumínio (comprimentos: $23 \mathrm{~cm}, 25 \mathrm{~cm}, 27 \mathrm{~cm}, 29 \mathrm{~cm}, 31 \mathrm{~cm}$ e $33 \mathrm{~cm}$; diâmetro interno $\emptyset_{\mathrm{i}}=12,2 \mathrm{~mm}$; diâmetro externo $\left.\emptyset_{\mathrm{e}}=16,0 \mathrm{~mm}\right)$;

2. cordão;

3. agulha e linha;

4. trena, transferidores, paquímetros, réguas, compassos;

5. tesoura;

6. acessórios de plástico para percussão e suspensão dos tubos, materiais que podem ser identificados na Fig. 1.

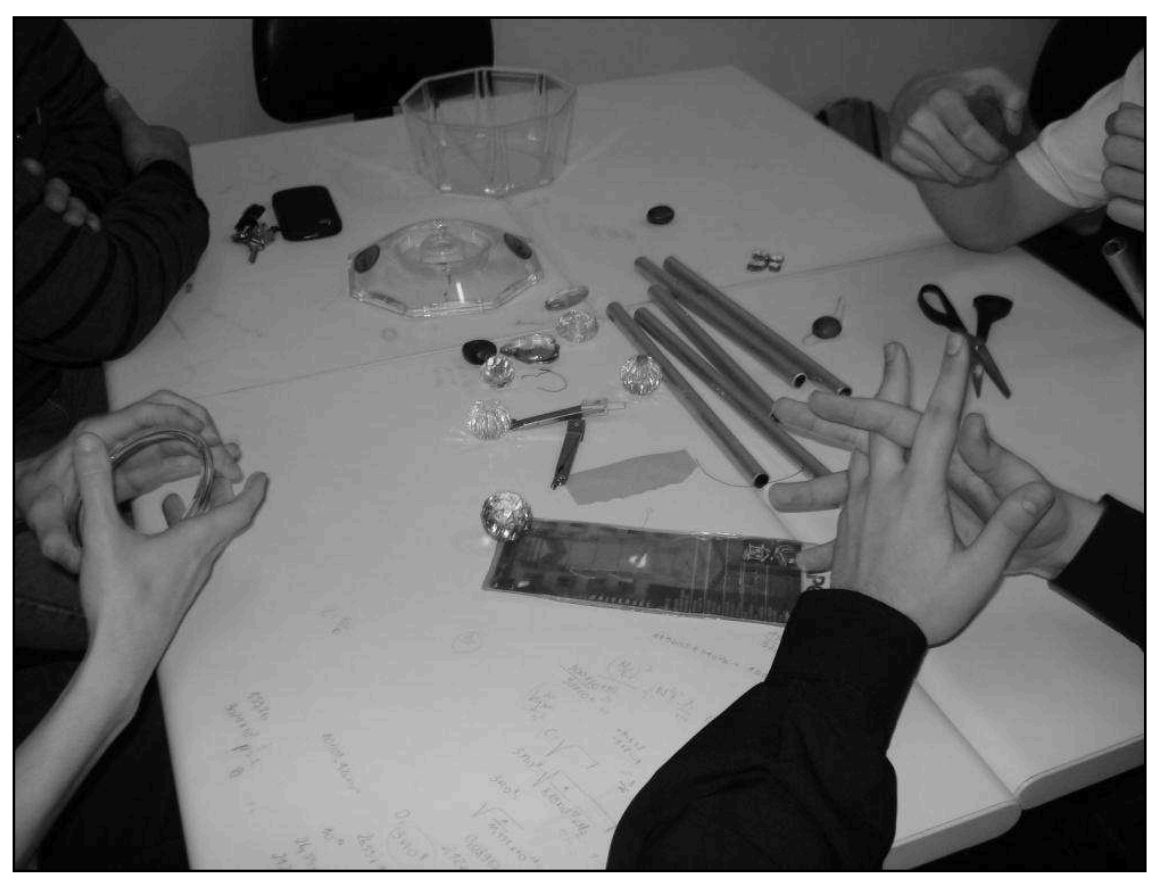

Fig. 1 - Materiais utilizados na construção do móbile. 
Além desses materiais, foram disponibilizados diversos móbiles para manipulação, a fim de facilitar a escolha de estratégias de montagem, uma vez que não foram oferecidas instruções na forma de roteiro (Fig. 2).

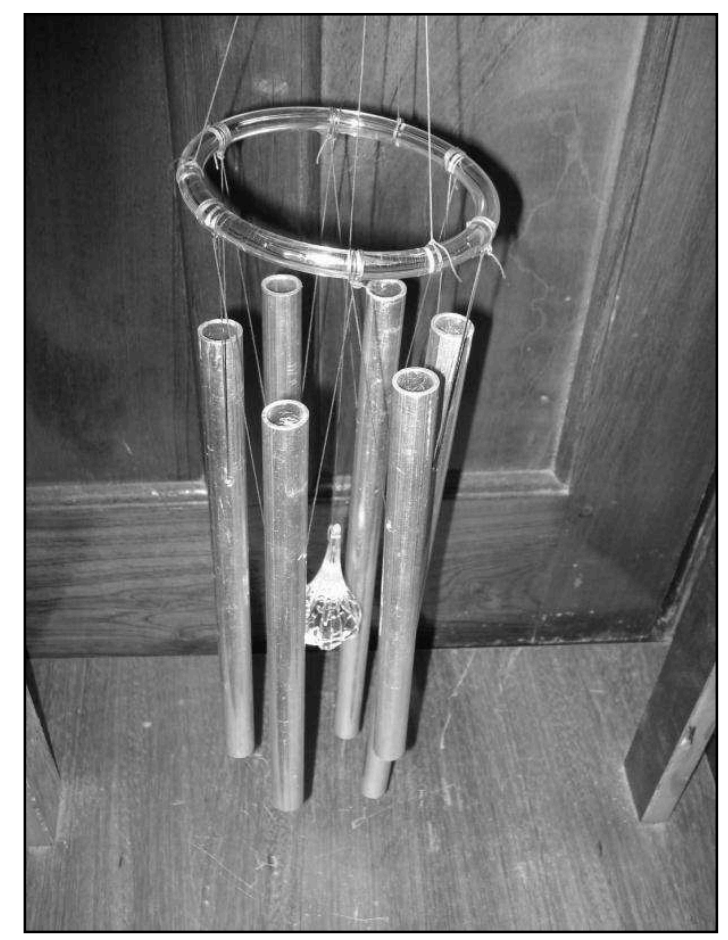

Fig. 2 - Um dos móbiles oferecido como exemplar.

A tarefa de suspensão dos tubos no suporte exigiu conhecimentos de geometria para demarcação dos pontos de suspensão de forma equidistante. Para que a divisão da circunferência em seis partes iguais fosse executada com êxito, fizeram-se necessárias intervenções pelos ministrantes da oficina para elucidar procedimentos de utilização do compasso para esse fim, face às dificuldades que surgiram (Fig. 3).

Além de aprendizagens cognitivas de ordem conceitual, a atividade de montagem do móbile propiciou o exercício e desenvolvimento de outras habilidades, como a da motricidade fina. Considera-se válida a vivência dessa construção pelo licenciando para que compreenda a importância desse tipo de prática ao seu futuro aluno com vistas ao desenvolvimento de habilidades cognitivas e motoras.

\section{II.2.2 Caracterização dos sons pela percepção e experimentação com instrumentos musi- cais e afinadores}

Para o estágio de caracterização dos sons foram utilizados os seguintes recursos:

- móbiles;

- afinadores;

• violão; 
- teclado;

- diapasão e

- software AP Guitar Turner 1.02 (AUDIO, 2014) e Oscilloscope 2.51 (ZELDOVI$\mathrm{CH}, 2014)$.

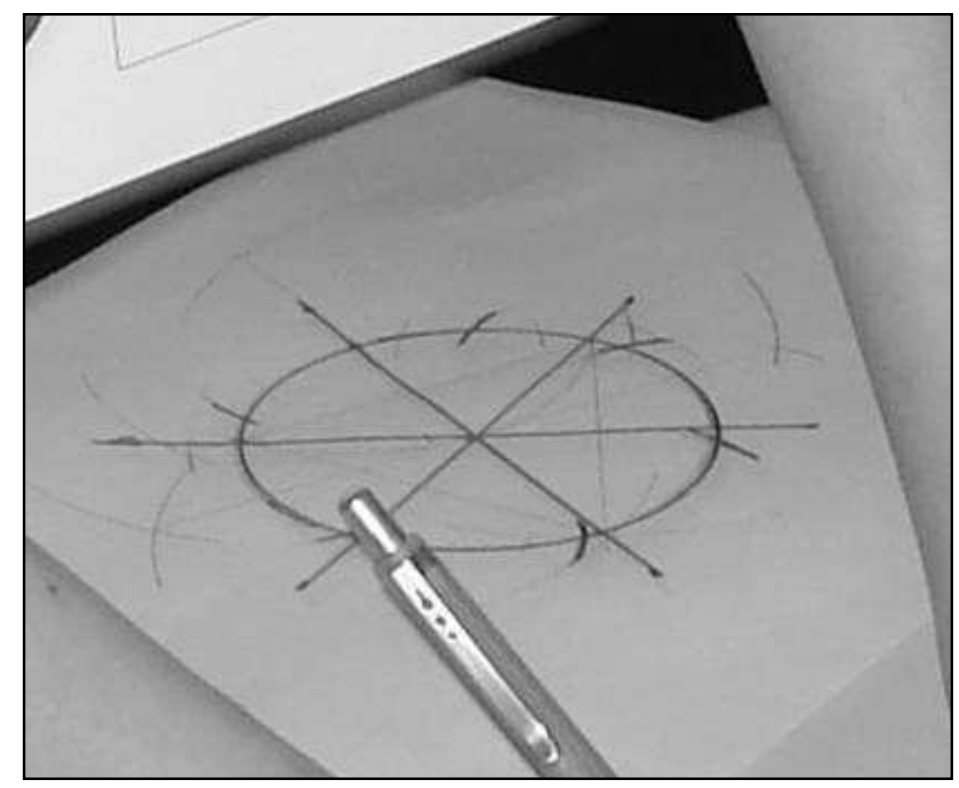

Fig. 3 - Exemplo de traçado feito pelo aluno para divisão da circunferência em seis partes iguais.

Alguns dos materiais acima citados podem ser identificados na Fig. 4.

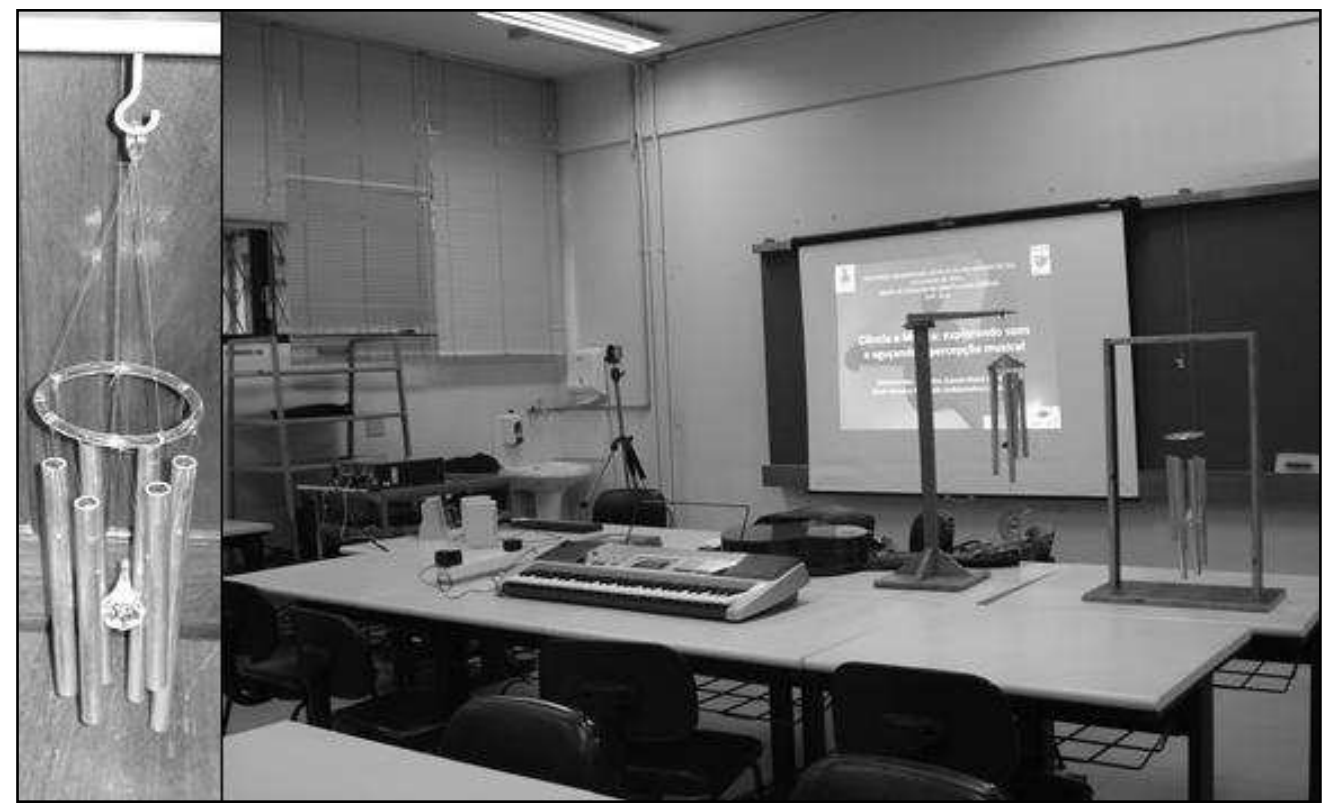

Fig. 4 - Recursos disponibilizados para caracterização dos sons. 
A identificação dos sons emitidos pelos tubos sonoros foi realizada primeiramente por percepção auditiva (Fig. 5), permitindo aos participantes comparar sons emitidos pelos tubos do móbile e as notas no violão, no teclado e no diapasão. Esse procedimento levou os alunos a aguçarem sua percepção na tentativa de identificar as notas musicais. A atividade foi facilitada pela presença nos grupos de alunos com conhecimento prévio sobre a produção das notas nas teclas do teclado e nas cordas do violão.

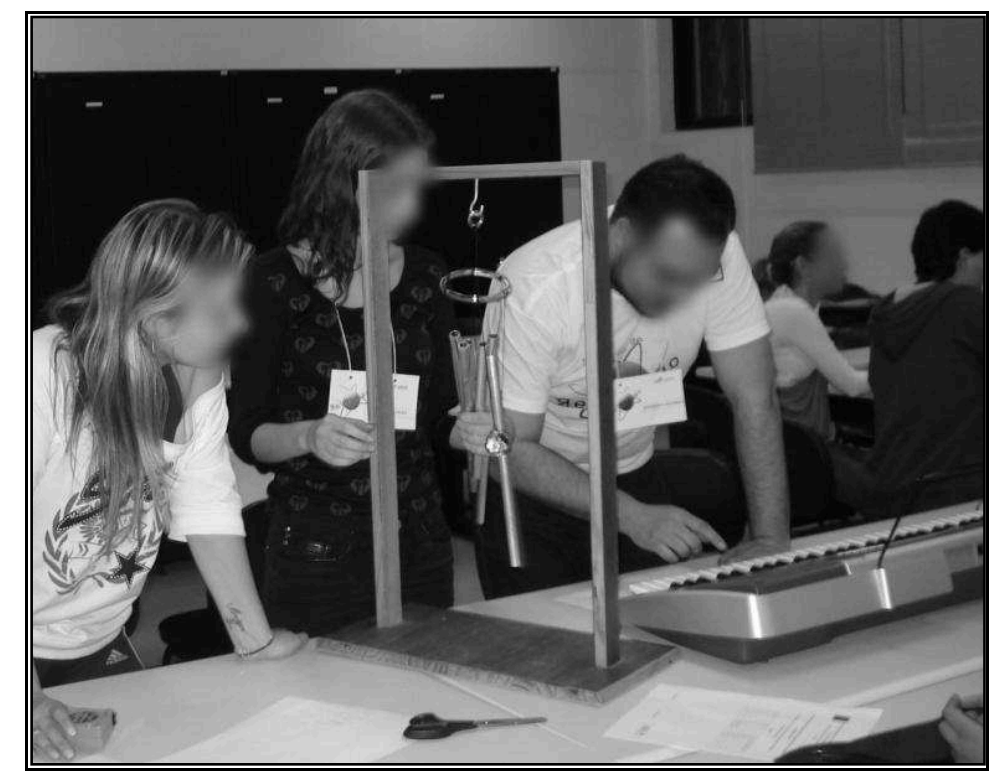

Fig. 5 - Identificação dos sons por percepção auditiva.

Esta atividade suscitou questionamentos sobre a fidedignidade de suas percepções. Disponibilizaram-se então afinadores capazes de identificar a nota correspondente ao som emitido e um quadro com as frequências e notas correspondentes no teclado (Fig. 6) do piano. Os ministrantes explicaram como o afinador pode ser utilizado para identificação das notas emitidas. Identificadas as notas no teclado, foi possível comparar os resultados lidos no afinador com os disponíveis no quadro da Fig. 6, permitindo ao aluno certificar-se acerca da exatidão dos resultados obtidos anteriormente de forma perceptiva, obtendo assim as notas e as frequências correspondentes.

A utilização dos afinadores e do quadro da Fig. 6 permitiu uma avaliação mais apurada do som (notas e frequências) e da própria percepção auditiva dos participantes (Fig. 7).

Nesta etapa também foram disponibilizados um afinador virtual (Fig. 8), o software AP Guitar Turner 1.02 (AUDIO Phonics, 2014), e um osciloscópio virtual, pelo software Oscilloscope 2.51 (ZELDOVICH, 2014). Com o uso desses recursos, pretende-se que o futuro professor familiarize-se e aproprie-se desses conhecimentos, pois em muitas escolas são mais viáveis do que instrumentos afinadores e também pela possibilidade de aplicação da informática no ensino, tendência essa que vai ao encontro da contemporaneidade tecnológica. 


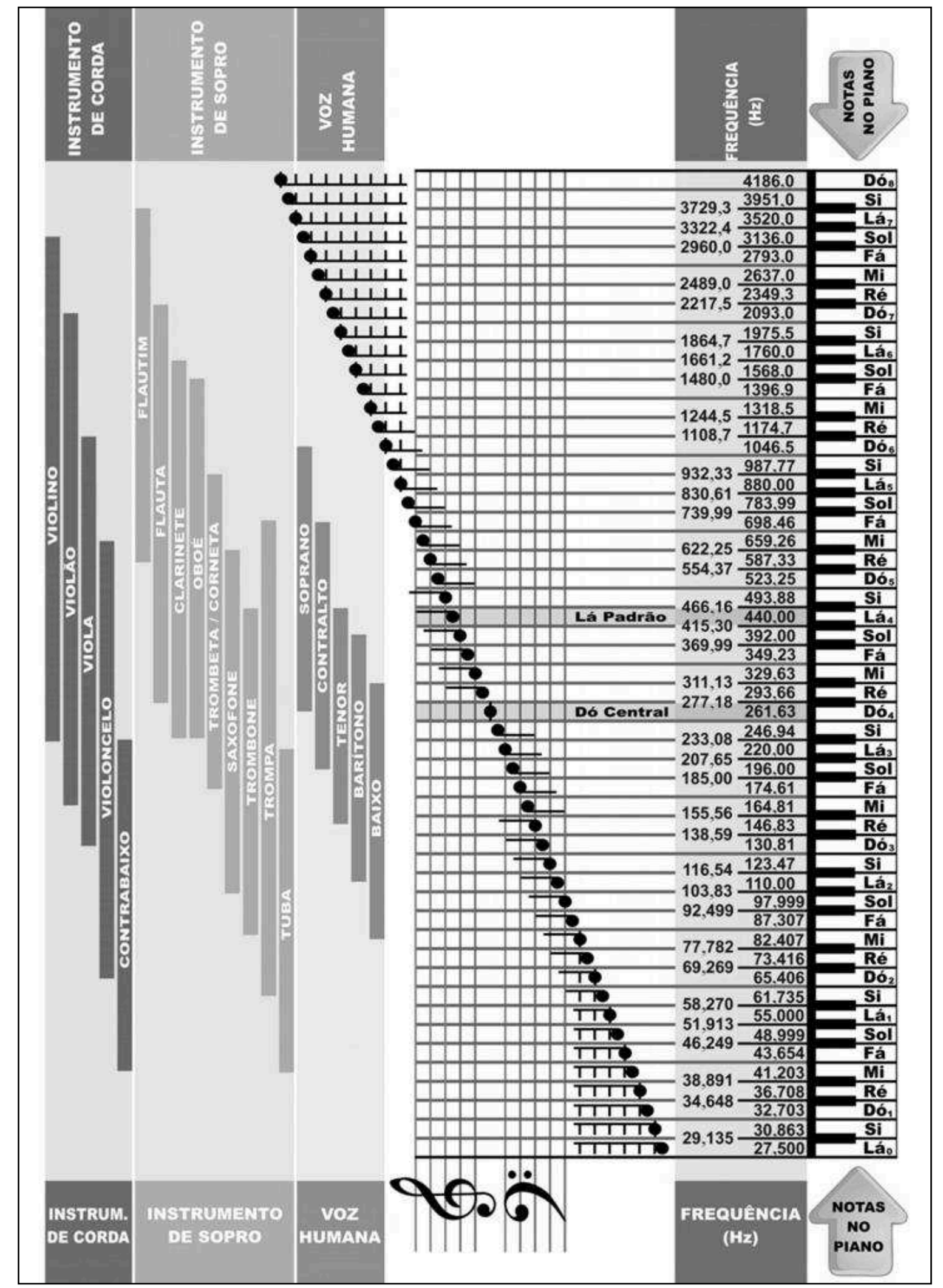

Fig. 6 - Notas e frequências no teclado do piano (MASLINKIEWICZ; COELHO, 2012, p. 91). 


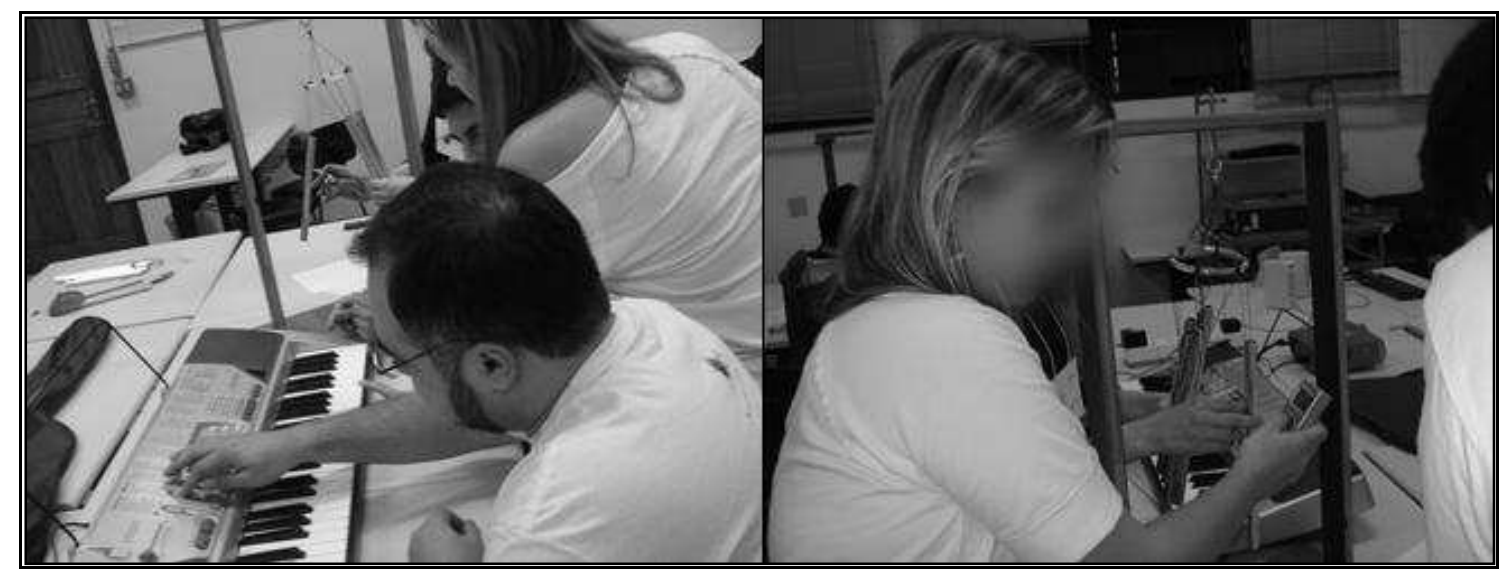

Fig. 7 - Identificação dos sons por métodos diferentes: pela percepção auditiva e por medição com afinadores.

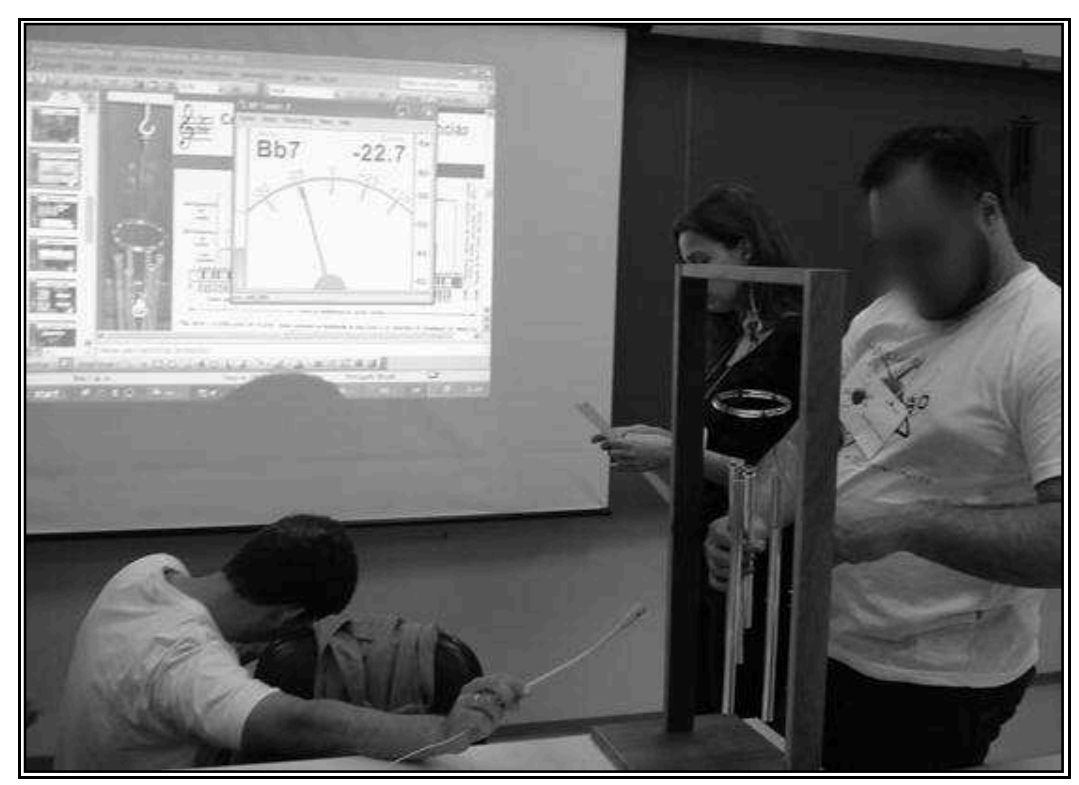

Fig. 8 - Medições com afinador virtual.

\section{II.2.3 A modelização matemática}

Segundo Halbwachs (1974, p. 40), "Conhecer uma situação é representá-la por um modelo". Neste processo de modelização procura-se compreender o que interfere no som emitido e quais são as variáveis pertinentes para a descrição do fenômeno, partindo de modelos mais simples para a exploração de modelos mais complexos, chamando a atenção para o campo de validade dos modelos e para a complexidade do real.

Foram considerados três modelos matemáticos válidos para cordas (violão e piano), tubos sonoros (estudo tradicional de tubos abertos e fechados) e barras percutidas. 
Inicialmente discutiu-se o modelo matemático para cordas aplicado ao violão e ao piano (teclado), identificando as variáveis pertinentes (comprimento da corda, densidade linear e tensão) que influenciam no som e sua relação com as qualidades desse som.

$$
\boldsymbol{f}=\frac{1}{2 \boldsymbol{l}} \sqrt{\frac{\boldsymbol{T}}{\boldsymbol{\mu}}} \quad \begin{aligned}
& \text { T - tensão } \\
& \begin{array}{l}
\mu \text { - comprimento } \\
\mathrm{f} \text { - frequensidade linear }
\end{array}
\end{aligned}
$$

Utilizou-se o princípio da causalidade como fonte importante para a exploração e compreensão do fenômeno - uma causa agindo sobre um sistema caracterizado por certas quantidades produz certo efeito segundo uma lei determinada -, o que auxiliou a identificação das variáveis pertinentes ao modelo, tendo o funcionamento do violão como referência no plano concreto (Fig. 9).

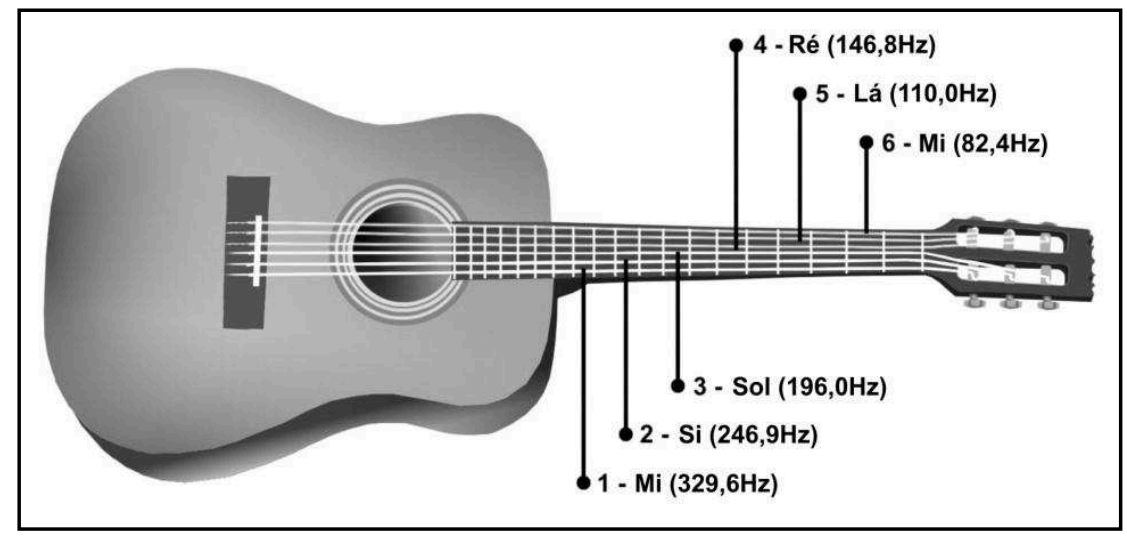

Fig. 9 - Frequências fundamentais dos sons emitidos e notas das cordas soltas de um violão afinado (PELOSI, 1993; VASCONCELOS, 2002; Henrique, 2008). Convém lembrar que o violão é um instrumento transpositor à oitava inferior, ou seja, por razões de ordem prática, as notas são escritas na partitura, com a clave de sol, uma oitava acima dos sons emitidos.

Também se situou historicamente o modelo das cordas, reportando ao monocórdio pitagórico e à questão das frequências sonoras.

A partir desse modelo, discutiu-se o caso dos tubos sonoros abertos e fechados, a ideia de modelo como aproximação e as diferenças entre os modelos, associando com os instrumentos de orquestra de sopro: quanto maior o comprimento do tubo mais grave é o som e menor a sua frequência, da mesma forma como ocorre no violão com relação ao comprimento da corda.

A terceira situação analisada foi a da barra percutida com as duas extremidades livres (OLSON, 1967), sendo este o modelo que mais se adequa para o caso do carrilhão e do móbile. A equação matemática que descreve o fenômeno sendo: 


$$
f=\frac{1,133 \pi}{\mathrm{I}^{2}} \sqrt{\frac{\mathrm{QK}^{2}}{\rho}} \quad K=\frac{\sqrt{\mathrm{R}_{\mathrm{e}}^{2}+\mathrm{R}_{\mathrm{i}}^{2}}}{2}
$$

No qual:

- $\mathrm{f}$ - frequência fundamental do modo transversal;

- Q - módulo de elasticidade;

- $\mathrm{R}_{\mathrm{i}}$ - raio interno;

- $\mathrm{R}_{\mathrm{e}}$ - raio externo;

- $\rho$-densidade do material;

- 1 - comprimento do tubo.
Para o alumínio:

- $\mathrm{Q}=69 \mathrm{Gpa}$

- $\rho=2,7.10^{3} \mathrm{~kg} / \mathrm{m}^{3}$

Para os tubos:

- $\mathrm{R}_{\mathrm{i}}=0,00620 \mathrm{~m}$

- $\mathrm{R}_{\mathrm{e}}=0,00795 \mathrm{~m}$

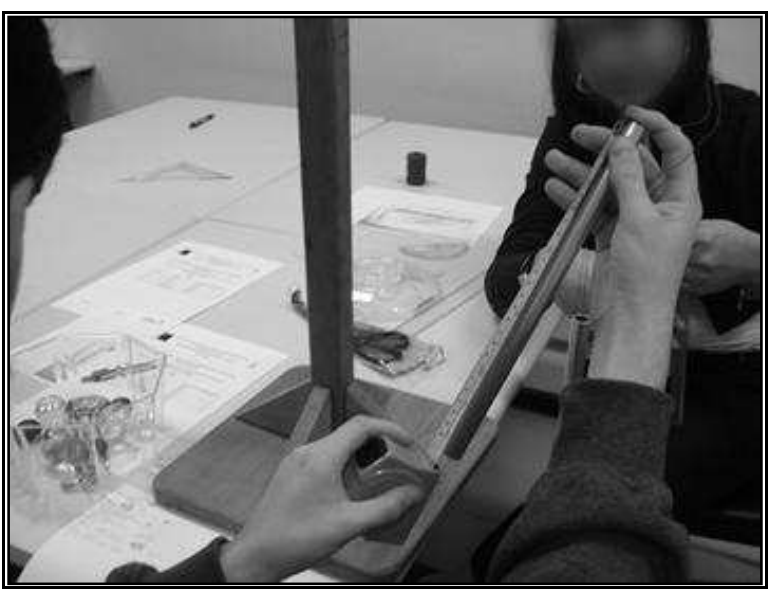

Fig. 10 - Alunos medindo as dimensões do tubo.

A Tabela 1 apresenta um exemplo de resultados obtidos a partir do modelo teórico para barra percutida e experimentalmente com o auxílio de afinadores.

Tabela 1 - Exemplo de resultados obtidos com o cálculo a partir do modelo teórico e experimentalmente (afinadores).

\begin{tabular}{cccc}
\hline $1(\mathrm{~m})$ & $\begin{array}{c}\text { Frequência calculada } \\
\mathrm{f}(\mathrm{Hz})\end{array}$ & $\begin{array}{c}\text { Notas determinadas nos } \\
\text { afinadores concreto e } \\
\text { virtual }\end{array}$ & $\begin{array}{c}\text { Frequências registradas na } \\
\text { Fig. 6 correspondentes às } \\
\text { notas f (Hz) }\end{array}$ \\
\hline 0,2320 & 1685 & G\#6 & 1661,2 \\
0,2492 & 1461 & F6 & 1396,9 \\
0,2688 & 1255 & D\#6 & 1244,5 \\
0,2880 & 1094 & C6 & 1046,5 \\
0,3085 & 953 & A\#5 & 932,3 \\
0,3288 & 839 & G\#5 & 830,6 \\
\hline
\end{tabular}

Fonte: Resultados obtidos pelos alunos. 
Nessa abordagem percebe-se que na física é necessário lidar com incertezas e discrepâncias que surgem em função do enfoque adotado no estudo do fenômeno. Não existe uma verdade absoluta; o modelo tem um limite de validade.

É possível avaliar de forma qualitativa: (a) as implicações do uso dos diferentes modelos; (b) que tipo de conhecimento a abordagem didática utilizando a modelização matemática proporciona; (c) a incerteza proveniente da percepção, da medição e da aproximação por modelo matemático.

Saber escolher o modelo, identificar as variáveis pertinentes, ver os limites de validade do modelo, compreender que o modelo não é o mundo real, mas é uma forma de se aproximar do mesmo e que existem vários modelos possíveis são conhecimentos e habilidades que a proposta possibilitou.

Considera-se que por este tipo de abordagem interdisciplinar que relaciona teoria e prática e diferentes campos de saber o professor produz conhecimento útil que passa a ter maior significado para o aluno. De forma implícita, como pano de fundo, deixa perpassar questões filosóficas sobre o funcionamento da ciência.

\section{II.2.4 Carrilhão na orquestra sinfônica}

A exemplificação do uso do carrilhão ${ }^{3}$ na orquestra sinfônica vem ao encontro do caráter interdisciplinar da proposta ao objetivar a integração de conhecimentos de ciência e música. Tanto o móbile utilizado com finalidade decorativa ou religiosa quanto o carrilhão de orquestra são instrumentos de percussão cujo funcionamento apresenta similaridades. Essa aproximação é importante do ponto de vista cultural e científico. Ao compreender cientificamente o comportamento do móbile, é possível transpor esse conhecimento para o carrilhão, fazendo o aluno perceber a aplicação desse conhecimento na execução de obras musicais por uma orquestra sinfônica e, portanto, sua utilidade e importância sob o ponto de vista da cultura musical.

Essa integração entre arte e ciência auxilia na construção de uma visão global da realidade e na superação do distanciamento entre o que é ensinado e a realidade.

Foi apresentada a música Abertura 1812 de Tchaikovsky (WONG, 2007) como fechamento da oficina. Essa obra comemora o fracasso da invasão francesa à Rússia em $1812 \mathrm{e}$ a subsequente derrota de Napoleão. Deixa evidente a importância do carrilhão como elemento na composição musical e seu papel na expressão de emoções ao imitar o efeito dos sinos das igrejas em seu final. Foi composta para a abertura da Exposição Universal das Artes, realizada

\footnotetext{
${ }^{3}$ Os sinos tubulares (ou carrilhão) usados na orquestra são constituídos por um conjunto de tubos em latão ou aço, de comprimentos graduados, como no caso das cordas do piano, todos tendo o mesmo diâmetro. Os tubos, abertos nos dois lados, têm dois orifícios perto de um extremo, através dos quais estão suspensos a uma estrutura. São tocados com um martelo de madeira (martelete) e existe um mecanismo de abafador, acionado por um pedal e/ou pela mão, que permite forçar a extinção das vibrações. No conjunto são 18 tubos ordenados cromaticamente em duas filas (à semelhança de um teclado de piano), e sua extensão vai de Dó3 até Fá4. Nas orquestras americanas, o número de tubos eleva-se a 20, permitindo obter ainda o Fá\#4 e o Sol4 (MASLINKIEWICZ; COELHO, 2012; HENRIQUE, 2008).
} 
em Moscou em 1882, na qual foram celebrados simultaneamente os 70 anos da vitória russa sobre Napoleão e o aniversário da coroação do Czar.

\section{Considerações finais}

O trabalho desenvolvido não representa uma receita de como usar a interdisciplinaridade, nem tampouco pretendeu abordar esse conceito de forma ampla e exaustiva. Constitui um exemplo de possibilidade didática associando conhecimentos de ciência e música, fugindo da fragmentação incitada pela rigidez dos programas.

A experimentação e a modelização matemática permitiram confrontos entre teoria e prática, apresentando-se como questão epistemológica implícita a relativização da verdade científica e a forma como se dá a construção do conhecimento científico.

A demonstração de interesse por parte de alguns alunos pela música e a curiosidade para aprender a tocar instrumentos musicais mostra que neste tipo de abordagem cria-se motivação e gosto pelo estudo de outros campos de conhecimento vizinhos ao do saber científico, o que também pode ocorrer no sentido inverso.

Permanece o questionamento se não deveríamos fazer um esforço no ensino das ciências para recuperar alguns traços da forma como a ciência se constrói, no caso interdisciplinarmente, rompendo a compartimentalização do conhecimento e dando ao aluno uma visão mais globalizada e próxima ao mundo real, integrando saberes de diferentes campos do conhecimento.

\section{Referências}

AUDACITY Software. Audacity 2.0. Software Freeware, Plataforma Windows, 2013. Disponível em: <http://audacity.sourceforge.net/?lang=pt> Acesso em: ago. 2014.

AUDIO Phonics. AP Guitar Tuner 1.02. Software Freeware, Plataforma Windows, 2009. Disponível em: <http://www.baixaki.com.br/site/dwnld48932.htm>. Acesso em: ago. 2014.

HALBWACHS, F. La pensée physique chez l'enfant et le savant. Neuchâtel: Delachaux et Niestlé, 1974.

HALBWACHS, F. La physique du maître entre la physique de l'élève et la physique du physicien. Revue Française de Pédagogie, v. 33, p. 19-29, 1975.

HELMHOLTZ, H. L. F. On the sensations of tone. New York: Dover, 1954.

HENRIQUE, L. L. Instrumentos musicais. 6. ed. Lisboa: Fundação Calouste Gulbenkian, 2008. 
LENOIR, Y. Didática e interdisciplinaridade: uma complementaridade necessária e incontornável. In: FAZENDA, I. (Org.). Didática e interdisciplinaridade. 17. ed. Campinas: Papirus, 2012. p. 45-75.

LÜCK, H. Pedagogia interdisciplinar: fundamentos teórico-metodológicos. 9. ed. Petrópolis: Vozes, 2001.

MASLINKIEWICZ, S.; COELHO, S. M. (Org.). Música, acústica e saúde fonoauditiva. Porto Alegre: Mundo das Óperas, 2012.

OLSON, H. F. Music, physics and engineering. 2. ed. New York: Dover Publications, 1967.

PELOSI, T. O caminho das cordas. Rio de Janeiro: Amais, 1993.

PIAGET, J. Para onde vai a educação? 2. ed. Rio de Janeiro: José Olympio, 1974.

POMBO, O. Interdisciplinaridade: ambições e limites. Lisboa: Relógio D’Água, 2004.

VASCONCELOS, J. Acústica musical e organologia. Porto Alegre: Movimento, 2002.

WONG, S. 1812 Overture - Tchaikovsky (Mercury Living Presence). Vídeo, 2007. Disponível em: <https://www.youtube.com/watch?v=k-vQKZFF-9s>. Acesso em: ago. 2014.

ZELDOVICH, Konstantin. Oscilloscope 2.51. Software Freeware, Plataforma Windows, 2008. Disponível em: <http://www.softpedia.com/progDownload/Oscilloscope-Download110132.html>. Acesso em: ago. 2014. 